molybdenum, yielding products which, in the case of cobalt and nickel, may prove to possess a commercial technical value, if prepared in large amounts.

\title{
A METHOD FOR THE RAPID DETERMINATION OF CARBON IN STEEL.
}

\author{
By KOBERT JOB AND ChaRles T. DAvies. \\ Received September 25, 1900.
}

\begin{abstract}
$A$ FTER a very thorough trial of Dr. Sargent's apparatus for $A$ the rapid determination of carbon, ${ }^{1}$ an investigation was begun with the object of retaining the continuous heating arrangement, and of reducing the apparatus to the simplest possible form without impairing in any way the accuracy of the results.
\end{abstract}

At the outset it was found that the separate, water-jacketed, copper oxide tube could be entirely eliminated by simply increasing the length of the combustion furnace to 9 inches, increasing the length of the porcelain combustion tube to 20 inches, and inserting closely rolled copper gauze about 4 inches in length, thoroughly oxidized prior to use, into the combustion tube, exactly as in the old method, placing pieces of clay-pipe stems between the copper oxide and the end of the tube in order to prevent the former from being forced out of place when the boat was run up against it in the determination.

Experiments with the furnace itself showed that three Bunsen burners each about $2 \frac{1}{4}$ inches apart, having spreaders upon the tops, furnished sufficient heat to keep the porcelain tube at a bright red heat over 8 inches of its length. A thin sheet-iron shield was placed just beneath the tube as a protection from the direct action of the flame.

After the removal of the separate copper oxide tube, it was found that the gases, upon reaching the calcium chloride tube preceding the weighed bulbs, had been cooled to the temperature of the room, so that the condensing worm was no longer necessary, and further test after its removal proved that the excess of water remaining in the gas at that point was small, and was readily removed by the calcium chloride without necessity of $f$ quent changing. It was further proved that the absorption

1 his Journal, 22, 277. 


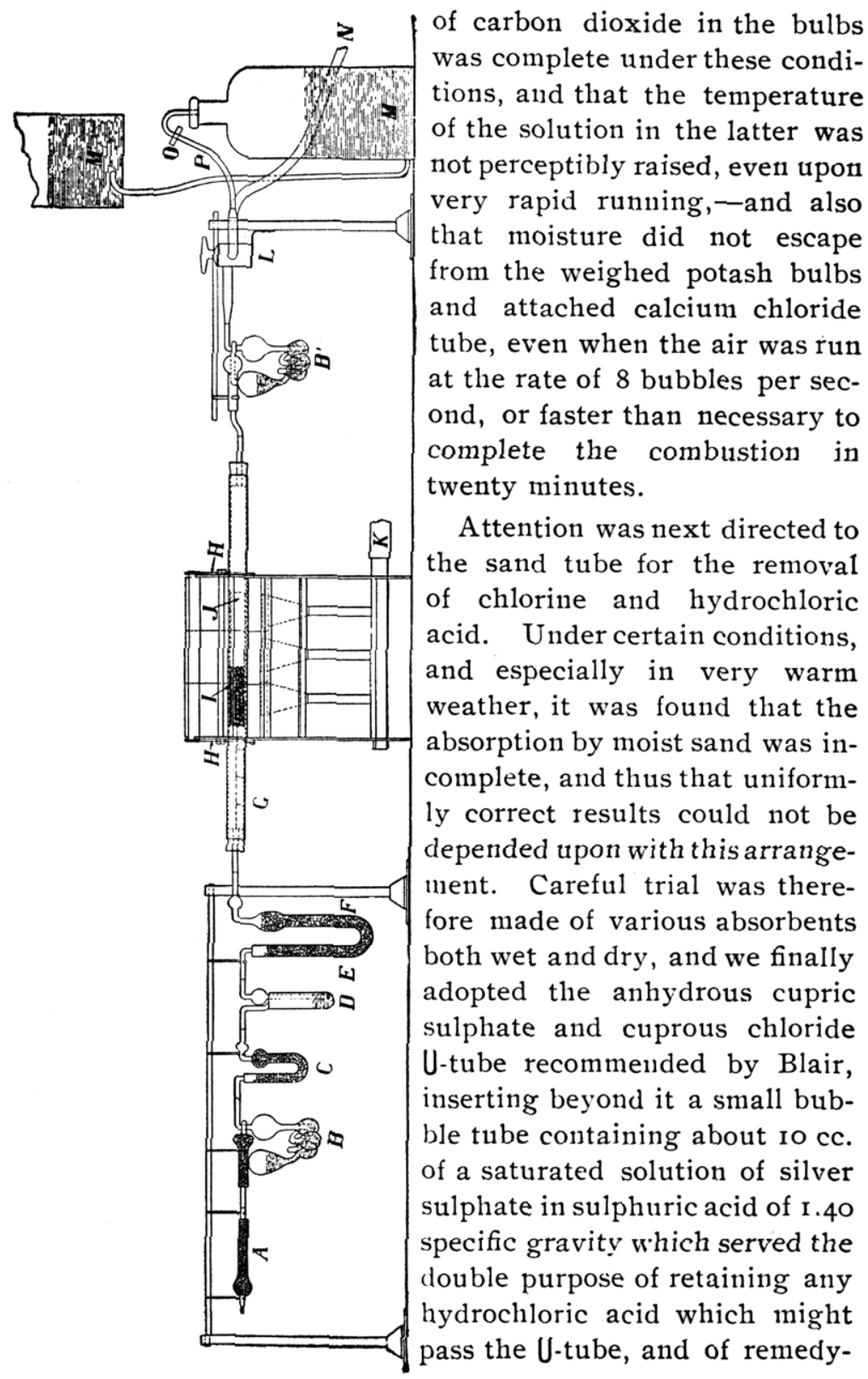


ing the excessive dehydration produced by the copper salts. The U-tube, E,F, is of the ordinary 6 inch form, and when filled contains cupric sulphate in the arm F, and cuprous chloride in $E$, both salts being freshly and thoroughly dehydrated, the copper sulphate being nearly white, and the cuprous chloride a dull brown. A small piece of glass wool is placed at the bottom of the tube to separate the salts, and also upon the top. The materials should be in granular form about $\frac{1}{8}$ inch in diameter, free from powder.

After once fllling the tube it may be safely used without change until the copper sulphate on the top of the arm $F$ becomes slightly blue or green, or until traces of hydrochloric acid begin to be caught in the silver sulphate solution. The tube should then be removed, placed upon the steam table, or otherwise heated, and a slow suction applied until the cupric sulphate has become nearly white. A second U-tube is kept on hand ready for use and is inserted while the other is being dehydrated. Heating and aspirating for an hour will generally produce the proper dehydration, and the tube is then capped and hung up ready for use. As a general thing a large number of determinations may be made without changing the tube.

The silver sulphate bubble tube, $\mathrm{D}$, is about $4 \frac{8}{4}$ inches in height, and $\frac{7}{8}$ inch in diameter, holding about $25 \mathrm{cc}$, if full. When in use the tube contains from 5 to ro cc. of the silver sulphate solution, this being blown in from a small wash-bottle. The tube is refilled after a determination if any precipitate has formed. This, however, seldom occurs unless the copper salts have become partially hydrated.

The calcium chloride tube, $\mathrm{C}$, next to the silver sulphate tube retains the excess of moisture from the latter, and the gas passes into the potash bulbs in precisely the same degree of dryness as it emerges from the calcium chloride tube attached to the weighed bulbs, as shown by the fact that in the blank determinations there is almost invariably neither loss nor gain in the weight of the bulbs.

In filling the calcium chloride tubes care should be taken that the material be freshly dehycrated, and in granular pieces about $\frac{1}{8}$ inch in diameter and free from dust. The tubes should be filled as completely as possible, tapping lightly upon them and 
filling close to the top, placing a very small piece of cotton at each end.

The potash bulbs, B and B', are practically the same as those recommended by Dr. Sargent, and hold, when filled for use, about $35 \mathrm{cc}$. of potassium hydroxide and weigh, including the calcium chloride, about 80 grams. These bulbs may be safely used until they have absorbed 2.5 grams carbon dioxide after which they should be cleaned out and refilled with fresh potash solution of I. 27 specific gravity. The calcium chloride tube, which is about $2 \frac{3}{4}$ inches in length, and $\frac{1}{2}$ inch in diameter, should also be refilled with dehydrated material at the same time. The calcium chloride tube, C, immediately before the weighed bulbs, should be refilled in the same manner as soon as the material begins to appear slightly moist at the end nearest the silver sulphate tube. This will usually occur after about fifty determinations. The old calcium chloride when removed can be thoroughly dehydrated in a few minutes by heating in an iron or porcelain dish.

In the course of our work more or less difficulty was at first experienced owing to the cracking of the porcelain tube, especially so when the boats were not warmed before inserting. We found, however, that this could be completely remedied by putting into the combustion tube a piece of platinum foil bent into tubular form, and fitting the combustion tube closely, being careful to have the edges somewhat beveled so that the boat, when pushed in with the wire, would run up smoothly upon the foil, the object of the latter, being, of course, to withdraw the heat absorbed by the boat from a considerable area of the combustion tube instead of from a few points. The above was noted by Dr. Sargent in the paper above referred to.

Attention was next turned to the purity of the oxygen supply, in order to avoid the necessity for the preheating furnace. Investigation showed that commercial oxygen free from hydrocarbons could be readily obtained. Therefore, we merely stipulate with the order that the material shall be of this quality, and upon arrival of the tank run a blank determination, passing the oxygen for ten minutes and then the air in the usual manner. The final weight of the bulbs after forty minutes in the balance should not vary more than 0.2 of a milligram from the original weight. In case, however, a pure supply could not be obtained, 
thus necessitating preheating of the gas, we found that a separate appliance could be avoided by simply passing a copper tube through the combustion furnace, utilizing the heat of the 3 burners for the purpose. An apparatus of this nature was attached readily to the furnace by boring two quarter-inch holes in each end of the furnace just above, and slightly to one side of the spreaders of the Bunsen burners, running a seamless copper tube of $\frac{1}{4}$ inch outside diameter entirely through the furnace, out through the end and back upon the opposite side parallel to the first, having the tube in such position that the flame would not play directly upon it, but still so close that the heat would bring it to redness. The ends of this tube, after passing through the furnace, were bent down almost to the level of the desk, and then extended along to the connection of the oxygen supply beyond the three-way cock, $L$. With this length of about i 8 inches from the furnace, the ends of the copper remained cool under all conditions of service, and could thus be attached direct to the rubber tubes leading respectively to the oxygen and to the three-way cock, without any necessity for a water-cooling arrangement.

In the regular determinations we heat up the furnace by lighting the middle burner, turning up one-half for five minutes, then turning up full, at the same time turning up the two end burners one-half, and after five minutes giving the full flame. The tube will be red hot within fifteen minutes from the start, and ready for the day's determinations. If then a boat is in the tube it is pulled out with the wire hook quickly upon a porcelain tile, the weighed potash bulbs, after removing the capillary tips, are connected in position, and the oxygen started through the purifying bulbs, $B^{\prime}$, at the rate of about 4 bubbles per second. The determination boat is then removed from the oven, placed within the end of the tube and run quickly into position against the copper oxide with the wire, which is removed at once, and the gum stopper inserted. The oxygen is passed for seven minutes at the above rate, then shut off, and the threeway cock turned and air passed at the rate of about 6 or 7 bubbles per second for twelve and one-half minutes regulating the pressure as necessary by means of the clamp $O$, and passing about $I$ liter of air. The stopper is then removed from the end of the tube, 
the bulbs disconnected, and another set of previously weighed bulbs inserted and the second combustion proceeded with. Three weighed bulbs are used in running a set of determinations, and one of the same size but slightly lighter than the others is kept upon the opposite pan of the balances as a counterpoise. The weights are taken after letting the bulbs stand for forty minutes in the balances. The furnace remains hot throughout the day's work without attention.

As to accuracy of results with this apparatus, we have checked repeatedly upon various standard steels, and have obtained uniform and practically identical results with those obtained by the regular combustion method with a platinum tube.

In its present form the apparatus can be readily made by cutting down an old furnace; no water connections are required, the number of joints is reduced to a minimum, the cost of operation as well as the initial cost are greatly reduced below the cost of the old combustion method, a porcelain tube is as satisfactory and quick as a platinum tube, and the entire apparatus from end to end can be placed upon a table 5 feet long.

In this apparatus we have retained what seemed to be for our purpose the most desirable features of the various appliances now in use and wish to make due acknowledgment for them. ${ }^{1}$

We have found it very advantageous to rechlorinate the double chloride of copper and potassium solution after Dr. Sargent's method." As the solution gradually becomes neutral we find it desirable after rechlorinating to make addition of hydrochloric acid in sufficient amount to restore the original acidity, thus preventing the separation of salts, and increasing the rapidity of solution.

The acidity can be determined very easily by titrating $5 \mathrm{cc}$. of the rechlorinated solution with standard potassium hydroxide solution, taking as the end-reaction the point at which the ferric hydroxide just formed fails to go into solution after shaking. Titration is then made of $5 \mathrm{cc}$. of a solution of one part hydrochloric acid and i 3 parts water (the normal acidity of the double chloride solution) with a drop of neutral ferric salt as indicator, the end-point being determined as above; comparison of the

1 The potash bulbs and silver sulphate tube were made to order by Queen $\&$ co.

2 This Journal, 22, 2 Io. 
acidity of the two solutions with the volume of the solution rechlorinated will show the amount of hydrochloric acid needed.

LABORATORY OF THE PHILADELPHIA AND READING

RAILWAY COMPANY, READIXG, PA.,

September 13,1900 .

\section{DETERMINATION OF IRON IN MAGNETITE ORE BY THE SPECIFIC GRAVITY TEST. ${ }^{1}$}

BY JOSEPH W. RICHARDS.

Received October 22, rgos.

$M_{\text {ANY magnetite ores are simply mixtures of magnetite and }}^{\text {quartz. The dressing of such ores at the mines up to a }}$ salable percentage of iron is often an important matter, and in such cases the weight of the ore, as determined by its "feel," is the determining factor as to whether it should pass into the ore pile or to the dump. Every new streak of ore opened up brings new material to be thus classified. For such classification, the specific gravity of the ore, carefully taken on a good pair of scales, is of quite sufficient accuracy to answer all practical purposes. Indeed, in many cases, considering the difficulty of obtaining a small representative sample from a mixed lot of ore such as the chemist requires, the specific gravity test made on a considerable weight of sample pieces may be quite as satisfactory as an analysis. The various ways in which specific gravity may be practically determined on an ordinary good scale need not be discussed here; anywhere from I to 50 pounds of ore may be tested, according to the scale at hand, and the accuracy desired, and results usually obtained accurate to 0 . Io in any case, and often to 0.02 or 0.03 , in the specific gravity. Such variations would mean a variation of $\mathrm{I}$ to 3 per cent. on the iron content, according to the richness of the ore. With ores over 45 per cent. of iron, the variation or error need not be over 2 per cent. on the iron, in any case.

To facilitate such tests, I have calculated the following table of the specific gravity of mixtures of magnetite and silica, of specific gravity of 5.18 , and 2.66 respectively, for every I per cent. of iron contained, giving in each case also the percentages of magnetite and quartz in the mixture, the latter datum being of particular importance in valuing the ore.

1 Read at the October meeting of the Lehigh Valley Section of the American Chemical society. 